\title{
Interactive comment on "Assessing impacts of selective logging on water, energy, and carbon budgets and ecosystem dynamics in Amazon forests using the Functionally Assembled Terrestrial Ecosystem Simulator" by Maoyi Huang et al.
}

\section{Anonymous Referee \#1}

Received and published: 20 May 2019

General Comments: This is an excellently written manuscript, very readable, and all arguments and assumptions are clearly stated. The work is timely as there is a general deficiency amongst models (especially biogeochemical) to have the ability to reflect managed disturbances, especially partial disturbance such as thinning or selective harvest. This will also be useful for disturbance through beetle kill and drought as there are many post-disturbance structural and successional changes/trajectories that need better representation in models. The correct representation of the immediate pool

Printer-friendly version

Discussion paper 
changes (CWD, litter, etc) are essential.

Specific comments: 1. The other pool that is often neglected is the dead tree pool (snags; standing dead wood). I understand that addition of this pool would require a revision to FATES (not trivial) but harvest operations (especially thinning) can lead to live tree death from machine damage and windthrow. This will be more important for using FATES in temperate, coniferous systems and the varied biogeochemical legacy of standing versus downed wood is important (Edburg et al. 2011, Edburg et al. 2012). Maybe this could be mentioned in the discussion for future model development? 2 . The results for GPP and NPP recovery are interesting. It is my understanding though that there is no Nitrogen limitation on growth in FATES (versus CLM; the non-ED version). The model is underestimating GPP and AR and in this case, it is not because of $N$ limitation (in the model). It appears it is low LAl; if this is 'fixed' do you think GPP may then be overestimated and there will be issues with non-modeled nutrient limitation? Just something to think about.

Edburg, S. L., J. A. Hicke, P. D. Brooks, E. G. Pendall, B. E. Ewers, U. Norton, D. Gochis, E. D. Gutmann, and A. J. H. Meddens. 2012. Cascading impacts of bark beetle-caused tree mortality on coupled biogeophysical and biogeochemical processes. Frontiers in Ecology and the Environment 10:416-424. Edburg, S. L., J. A. Hicke, D. M. Lawrence, and P. E. Thornton. 2011. Simulating coupled carbon and nitrogen dynamics following mountain pine beetle outbreaks in the western United States. Journal of Geophysical Research-Biogeosciences 116.

Interactive comment on Biogeosciences Discuss., https://doi.org/10.5194/bg-2019-129, 2019.

Printer-friendly version

Discussion paper 